\title{
DEVELOPMENT OF ROUTINE RT-PCR ELOSA TESTS FOR FRUIT TREE CERTIFICATION
}

\author{
J. Kummert, M. Vendrame and \\ P. Lepoivre \\ Unité de Phytopathologie \\ Faculté Universitaire des Sciences \\ agronomiques \\ B-5030 Gembloux \\ Belgium
}

\author{
S. Steyer \\ Département de lutte biologique et \\ resources phytogénétiques \\ Centre de recherches agronomiques \\ B-5030 Gembloux \\ Belgium
}

Keywords: ACLSV, ASGV, ASPV, PDV, PNRSV, RT-PCR, Colorimetric detection, Crude extracts

\section{$\underline{\text { Abstract }}$}

Current developments in certification procedures for fruit tree multiplication matcrial require the availability for rapid, sensitive, reliable and user's friendly detection protocols applicable for routine testing. Our research concerns the possible use of RT-PCR for the detection of the viruses listed for the virus-tested material of pome- and stone-fruit multiplication material in Belgium.

Although RT-PCR allows to reach the demand for rapidity and sensitivity, the usual protocols relying on the use of purified nucleic acid preparations as template, and agarose gel electrophoresis for detection, are not appropriate for routine use.

The use of carefully optimised RT-PCR reactions allowing this reaction to be performed on crude extracts of fruit tree tissues associated to a colorimetric detection of amplification products in microtiter plates would render this technique easier to perform, and thus more adapted for routine testing.

Considering the high specificity needed for certification, a protocol using hybridisation of specific amplification products between labelled capture and detection probes has been retained. This has been achieved with the RT-PCR-ELOSA diagnosis system of Lambdatech S.A.(Namur, Belgium) using sandwich hybridisation of amplification products to spccific detection probe, labelled with biotin, and capture probe phosphorylated at its 5' end, covalently linked to microtiter plates.

Analysis of available sequence data has been used to define primers and probes responding to the constraints of size and structure of the Lambdatech system for the RTPCR-ELOSA detection of Apple chlorotic leafspot virus (ACLSV), Apple stem grooving virus (ASGV), Apple stem pitting virus (ASPV), Prunus necrotic ringspot virus (PNRSV) and Prune dwarf virus (PDV). The RT-PCR-ELOSA detection tests defined for these viruses are under evaluation.

\section{Introduction}

The large increase of the volume of the intra- and intercontinental commercial exchanges and the development of free economical exchanges area, increase the phytosanitary risks and reinforce the necessity for delivery of phytosanitary passports. In this context, phytosanitary certification is becoming more and more compulsory and is demanding for the availability of sensitive, reliable and rapid tests, practicable for routine application to large numbers of samples. This is specially the case for woody pcrennial plants for which the classical biological indexing is particularly time consuming.

Although PCR is largely uscd in research laboratories, pre- and post-amplification steps may represent major drawbacks for its application in routine tests. In research activities, the use of PCR (or RT-PCR) is most frequently applied to purified nucleic acid 
preparations for which the length, complexity or cost exclude their routine use.

The different steps, which have to be considered as a whole in the development of RT-PCR detection protocols, are the sample processing, the optimisation of RT-PCR reactions, including the choice of the primers, and the detection of the amplification products. For example, the correct design of the primers (based on several parameters as the sequence, the size, the annealing temperature, the absence of self-hybridisation,...) allows an efficient amplification, permitting in his turn their application to less purified extracts. Concerning the detection of the amplification products, we use the ELOSA technique (based on hybridisation of amplification products to 2 specific probes in microtitration plates, followed by a colorimetric enzymatic revelation) which possess the adequate characteristics of sensitivity and specificity. The length of the targeted amplification products and the presence of specific conserved sequences are important parameters for the definition of capture and detection probes, but they also depend on the correct choice of the primers.

The work presented concerns the development of RT-PCR diagnostic tests for certification of fruit-tree multiplication material (category Virus-Tested) using crude extracts of leaf and bark tissues of trees and colorimetric detection of specific amplification products. Such tests have been actually developed for the detection of Apple chlorotic leafspot virus (ACLSV), Apple stem grooving virus (ASGV), Apple stem pitting virus (ASPV), Prune dwarf virus (PDV) and Prunus necrotic ringspot virus (PNRSV) in apple, pear, plum and/or cherry trees.

2. Material and methods

\subsection{Plant material}

The plant matcrial used for the development of the RT-PCR protocols for the detection of ACLSV, ASGV, ASPV, PDV and PNRSV consisted in herbaceous host plants inoculated with characterized isolates and characterized virus-infected trees from collections bearing single or mixed infections.

The validation of the optimised RT-PCR protocols developed has been conducted on samples taken on trees in the fields, or budwood from collections, orchards and nurseries.

\subsection{Sample processing}

Total RNA preparations were obtained from $0.5 \mathrm{~g}$ of leaf or bark tissues, ground in liquid nitrogen with pestle and mortar by the technique of Bugos et al. (1995) for apple- and pear-trees and of Spicgcl et al. (1996) for plum- and cherry-trees.

Crude extracts were obtained by grinding fresh bark or leaf tissue in the SCPAP buffer (Minsavage et al., 1994) in a $1 / 10$ (w/vol) ratio. After low speed centrifugation, the crude extracts were diluted in the same buffer. Tissues were ground in Eppendorf tubes with pellet, in the presence of insoluble polyvinylpyrrolidone, or in plastic bags containing a nylon grid (Bioreba).

\subsection{Design of specific primers and probes}

The specific primers and probes for ACLSV, ASGV, ASPV, PDV and PNRSV were selected by computer analysis with PILEUP, FASTA and PRIME programs [Wisconsin Package Version 10.0, Genetic Computer Group (GCG), Madison, Wisc., USA]. These programs were applied to sequence data available in EMBL and Genbank databases as well as partial sequences obtained in the laboratory, in order to mect the technical requirements of both the RT-PCR reaction and the colorimetric revelation of specific amplification products using sandwich hybridisation with a capture and a detection probes. 


\subsection{RT-PCR amplification}

RT-PCR amplifications were performed by using the Titan ${ }^{\mathrm{TM}}$ one tube RT-PCR system from Roche with selected specific primers. A $25 \mu$ l RT-PCR reaction mixture containing $0.2 \mathrm{mM}$ of each dNTPs, $0.4 \mu \mathrm{M}$ of both primers, and the reagents from the Titan $^{\mathrm{TM}}$ one tube RT-PCR system was submitted to a cDNA synthesis $\left(30 \mathrm{~min}\right.$ at $\left.55^{\circ} \mathrm{C}\right)$ and to a PCR amplification with a denaturation of 2 min at $94^{\circ} \mathrm{C} ; 40$ cycles of $30 \mathrm{sec}$ at $94^{\circ} \mathrm{C}, 45 \mathrm{sec}$ at $55^{\circ} \mathrm{C}, 1 \mathrm{~min}$ at $72^{\circ} \mathrm{C}$; and a final extension of $10 \mathrm{~min}$ at $72^{\circ} \mathrm{C}$.

\subsection{Detection of amplification products}

\subsubsection{Gel electrophoresis}

Amplification products were analysed by electrophoresis of $10 \mu \mathrm{l}$ of the reaction mixture in $1.5 \%$ agarose gel in Tris-acetate-EDTA buffer and bands visualized under UV by ethidium bromide staining (Sambrook et al., 1989).

\subsubsection{Colorimetric detection in microplates}

The specific amplification products were detected after sandwich hybridisation in microtiter plates or strips between a covalently linked capture probe and a 5 ' biotinylated detection probe. Both the capture and detection probes are part of detection kits in development (Lambdatech S.A., Belgium). The capture probes are produced by PCR using specific RT-PCR amplification products cloned in plasmid vector PCR 2.1 (TA cloning kit, Invitrogen). The forward primer used for synthesis of a capture probe corresponds to the forward primer used in the RT-PCR reaction, shortened at its 3' and modified at its 5' end by a phosphate group. The reverse primer corresponds to a internal sequence of the targeted RT-PCR product. The capture probe produced by PCR is denatured and immobilised on the plastic of the plate (Covalink, Nunc) by the protocol described by Rasmunssen et al. (1991). The single stranded detection probe, biotinylated at its 5' end is selected in a conserved region of the RT-PCR amplicon, and non complementary to the capture probe. Prior to the hybridisation, the amplicons were denatured $10 \mathrm{~min}$ at $100^{\circ} \mathrm{C}$. A hybridisation at $55^{\circ} \mathrm{C}$ for $2 \mathrm{~h}$ was then performed between the capture probe, the denatured amplification product and the detection probe. A streptavidin-peroxidase conjugate was used for detecting the nucleic acid hybrids. The revelation was performed after adding the revelation solution $\left(3,3^{\prime}, 5,5^{\prime}\right.$ tetramethylbenzidine) and incubating the plate in the dark for $10 \mathrm{~min}$ at room temperature. The enzymatic reaction was stopped by addition of sulphuric acid. The hybridisation and the washing buffers are those recommended by the manufacturer (Lambdatech S.A.). The optical density values were measured at $450 \mathrm{~nm}$ in a spectrometer Titertek Multiscan Plus.

\section{Results and discussion}

\subsection{Selection of primers and probes}

The Wisconsin Package Version 10.0 of Genetic Computer Group (GCG), Madison, Wisc., USA has been used for analysis and comparison of sequences and research of potential primers and probes.

For the different viruses concerned, we use sequences from EMBL and Genbank databases as well as sequences kindly received from colleagues, collected from publications and also some partial sequences determined from local isolates. For ACLSV, ASGV and ASPV, the higher levels of homology have been found in the 3 ' end of the genes coding for the RNA polymerase and the coat protein, and the 3' end non coding regions. For PDV and PNRSV, the sequences of the subgenomic RNA4 were used, as 
most of the sequences available for different isolates concern this RNA. These regions were chosen for research of primers pairs (21-25 nt long) amplifying a 250-350 bp fragment, using the programme Prime. Amongst the several potential primers thus obtained only very few can be retained after comparison with the alignment of the sequences of different isolates available for each virus. Finally primers pairs ACLSV5F8R, ASGV5F-5R, ASPV4F-4R, PDV17F-12R and PNRSV10F-10R have been selected and validated for RT-PCR amplification reactions.

The samc approach has been used for the definition of the primers used for synthesis of the capture probes and of the detection oligonucleotide probes.

\subsection{Optimisation of RT-PCR}

For RNA target sequences, as it is the case for the viruses concerned, the amplification has to be preceded by a reverse transcription step. Previous works concerning.RT-PCR detection of different RNA viruses have shown that the « Titan one tube RT-PCR system" (Roche diagnostic) give us the best results in terms of reproducibility and sensitivity (Kummert et al., 1998; Marinho et al., 1998 ; Chandelier et al., 1998). This one tube system allows both reactions to be performed in a single optimised buffer in the presence of enzymes (AMV reverse transcriptase, Taq and PWO DNA polymerases) dNTPs, primers and target sequences.

For all five viruses, the RT-PCR amplification reactions have been optimised by using total RNA preparations from herbaceous hosts or trees infected with characterized virus isolates. As the optimised thermal cycles were very similar for the RT-PCR reactions developed for the five specific primers pairs, a single cycle has been finally retained for all five viruses as follows: $30 \mathrm{~min}$ at $50^{\circ} \mathrm{C} ; 3 \mathrm{~min}$ at $94^{\circ} \mathrm{C} ; 30 \mathrm{sec}$ at $94^{\circ} \mathrm{C} ; 45$ $\mathrm{sec}$ at $55^{\circ} \mathrm{C} ; 60 \mathrm{sec}$ at $72^{\circ} \mathrm{C}(40 \mathrm{cycles}) ; 10 \mathrm{~min}$ at $72^{\circ} \mathrm{C}$.

\subsection{Sample processing}

Although RT-PCR is largely used in research laboratories, pre- and postamplification steps may represent major hindrances to its adoption for routine use. For research works, PCR is generally applied to purified nucleic acids for which the preparation techniques are not adapted to routine use on large samples, as needed for certification. The direct use of crude extracts will constitute the ultimate simplification of the RT-PCR assays. As plant tissues often contain components which interfere with the enzymes used for amplification, the crude extracts have to be significantly diluted (Rohwani et al., 1995). The use of crude extracts also requires then the strictest selection of the primers and design of the RT-PCR reaction. Different buffers and additives have been tested for grinding plant tissues and diluting the crude extracts. Best results were obtained when the SCPAP buffer of Minsavage et al. (1994) is used for both grinding and preparation of the dilutions of crude extracts.

The optimised RT-PCR protocols developed for the detection of the five viruses from diluted crude extracts have been shown efficient when applied to representative characterized virus-infected trees. For ACLSV, ASGV and ASPV, the optimised protocols have been validated by application to a large collection of virus-infected materials from different origins. They have been shown efficient for the specific detection of these 3 viruses, notably for the control of in vitro grown multiplication material. They can also reliably be applied all year long on orchard tree material, even when applied to dormant wood (scions).

For ACLSV, which shows an uneven distribution of the virus within an infected tree, this technique has been shown more sensitive than the ELISA tests.

\subsection{Detection of amplification products}

To obtain a gain in sensitivity and convenience in the specific detection of 
amplification products, colorimetric detection protocols have been developed. Considering the high specificity needed for certification, only protocols using sandwich hybridisation of the amplification products with a capture and a detection probes have been retained and the design of the (RT)-PCR ELOSA detection test from Lambdatech S.A. (Namur, Belgium) has been adopted. This ELOSA detection protocol uses a capture probe synthesized by PCR from cloned target sequences and an oligonucleotide detection probe.

The comparison of the sequences of different isolates available for the genome fragment amplified with the primer pairs selected for the RT-PCR amplification reactions for all five viruses allowed us to define oligonucleotide detection probes and primers for the synthesis of capture probes. Detection probes corresponding to conserved sequences located near to the 3 ' end of the amplification products are custom-synthesized with a biotin labelling at their 5' end. Capture probes are synthesized by PCR from cloned characterized RT-PCR amplification products containing the fragment delimited by the primers pairs selected for the RT-PCR-ELOSA detection tests and obtained from total RNA preparations from plants infected by a single known virus isolate. The forward primers used for synthesis of capture probes correspond to the forward primers of the RTPCR, shortened and phosphorylated at their 5' end; the reverse primers correspond to an internal conserved region of the amplification product. The capture probes thus defined can be easily and reproducibly produced from homogeneous plasmid DNA.

The ELOSA detection protocols have first been developed and optimised by using cloned target DNA sequences corresponding to specific RT-PCR amplification products from plants infected with characterized ACLSV, ASGV, ASPV, PDV or PNRSV isolates. For this optimisation, all the buffers and protocols used were those of Lambdatech S.A. Following this optimisation, the controlled functional protocol retained for ELOSA detection of amplification products targeted for the five viruses with the probes selected uses $20 \mathrm{ng}$ of detection probe/well, $300 \mathrm{ng}$ of detection probe/well fixed at $50^{\circ} \mathrm{C}$ to aminated microplates/strips and a hybridisation of both probes to specific amplification products at $55^{\circ} \mathrm{C}$ for 2 hours. These optimisation assays made with cloned DNA target sequences have shown that the ELOSA protocols allowed the detection of about $1 \mathrm{ng}$ of target DNA, which can readily be obtained in diluted preparations from RT-PCR amplification reactions even obtained from crude extracts.

The ELOSA detection protocols have thus been used for the detection of specific RT-PCR amplification products obtained from crude extracts of bark and leaf tissues of apple, pear, plum and cherry trees from the orchards and in vitro grown virus-infected plantlets.

Figure 1 shows the results obtained for the ELOSA detection of RT-PCR amplification products obtained from crude extracts of ACLSV-infected apple tree B8. For this assay, a good correlation has been observed between the colorimetric revelation by ELOSA and electrophoretic analysis in ethidium bromide stained agarose gel (results no shown), both being more sensitive than the ELISA test conducted on the same extracts.

Figure 2 shows the results obtained for the ELOSA detection of RT-PCR amplification products obtained from crude extracts of virus-infected plum and cherry trees with the primers pairs PDV17F-12R and PNRSV10F-10R. Here also a good correlation has been observed between the results of ELOSA detection and electrophoretic analysis and of the same amplification products.

4. Conclusions

If the use of molecular techniques like (RT)-PCR is actually widespread in research laboratories, their practical or routine use, for example in certification procedures, still encounter many objective difficulties or more subjective unwillingness from the potential users. In spite of their performances in terms of sensitivity and specificity, the complexity of these molecular techniques has remained a major obstacle. 
The advances brought to (RT)-PCR protocols allowing both the direct use of crude extracts and the revelation of specific amplification products by colorimetric reactions (ELOSA) render their routine use and partial auto detion of ACLSV, ASGV, ASPV, PNRSV and such RT-PCR ELOSA protocolsther leaf or bark tissues of fruit-trees. These protocols are PDV from crude extracts of evariability of the different isolates of the viruses concerned. being validated against the for certification needs the continuation of a global approach Their potential routine use sampling procedures which have to be adapted to the characteristics of the technique used and the object of its application.

\section{Acknowledgements} This research is funded by the Belgian Ministry of Small Enterprises, Traders and
Agriculture-DG6 (Research and development) + DG4 (Quality of Plants and Plant Products) and the European Commission-DGVI (Agriculture).

\section{References}

Bugos R.C., Chiang V.L., Zhang X.H., Campbell W.H., Podila G.K. and Campbell, W.R., 1995. RNA isolation from plant tissues recalcitrant to extraction in guanidine. Biotechniques 19: 734-737

Chandelier A., Cognet S., Marinho V.L.A., Kummert J. and Lepoivre, P., 1998. Development of routine detection tests using PCR for certification. Mededelingen van
het Faculteit van de Landbouwwetenschappen van het Universiteit te Gent 63/4b: 1473-1978.

Kummert J., Marinho V.L.A., Rufflard G., Colinet D. and Lepoivre P., 1998. Sensitive detection of apple stem grooving and apple stem pitting viruses from infected apple trees by RT-PCR. Acta. Horticulturae 472: 97-104.

Marinho V.L.A., Kummert J., Rufflard G., Colinet D. and Lepoivre P., 1998. Detection of apple stem grooving virus in dormant apple trees by using crude extracts as templates for one-step-RT-PCR. Plant Diseases 82: 785-790.

Minsavage G.V., Thompson C.M., Hopkins D.L., Leite R.M.V.B. and Stall R.E., 1994. Development of a polymerase chain reaction protocol for detection of Xylella fastidiosa in plant tissue. Phytopathology 84: 456-461.

Rasmussen S.R., Larsen M.R. and Rasmussen S.E., 1991. Covalent immobilisation of DNA onto polystyrene microwells: the molecules are only bound at then 5 ' end. Anal Biochem. 198: 138-142.

Rowhani A., Maningas M.A., Lile L.S., Daubert S.D. and Golino D.A., 1995. Development of a detection system for viruses of woody plants based on PCR analysis of immobilized virions. Phytopathology $85:$ 347-352.

Sambrook J., Fritsch E. and Maniatis T., 1989. Molecular cloning: A laboratory manual. New York, Cold Spring Harbor Laboratory. 


\section{Figures}

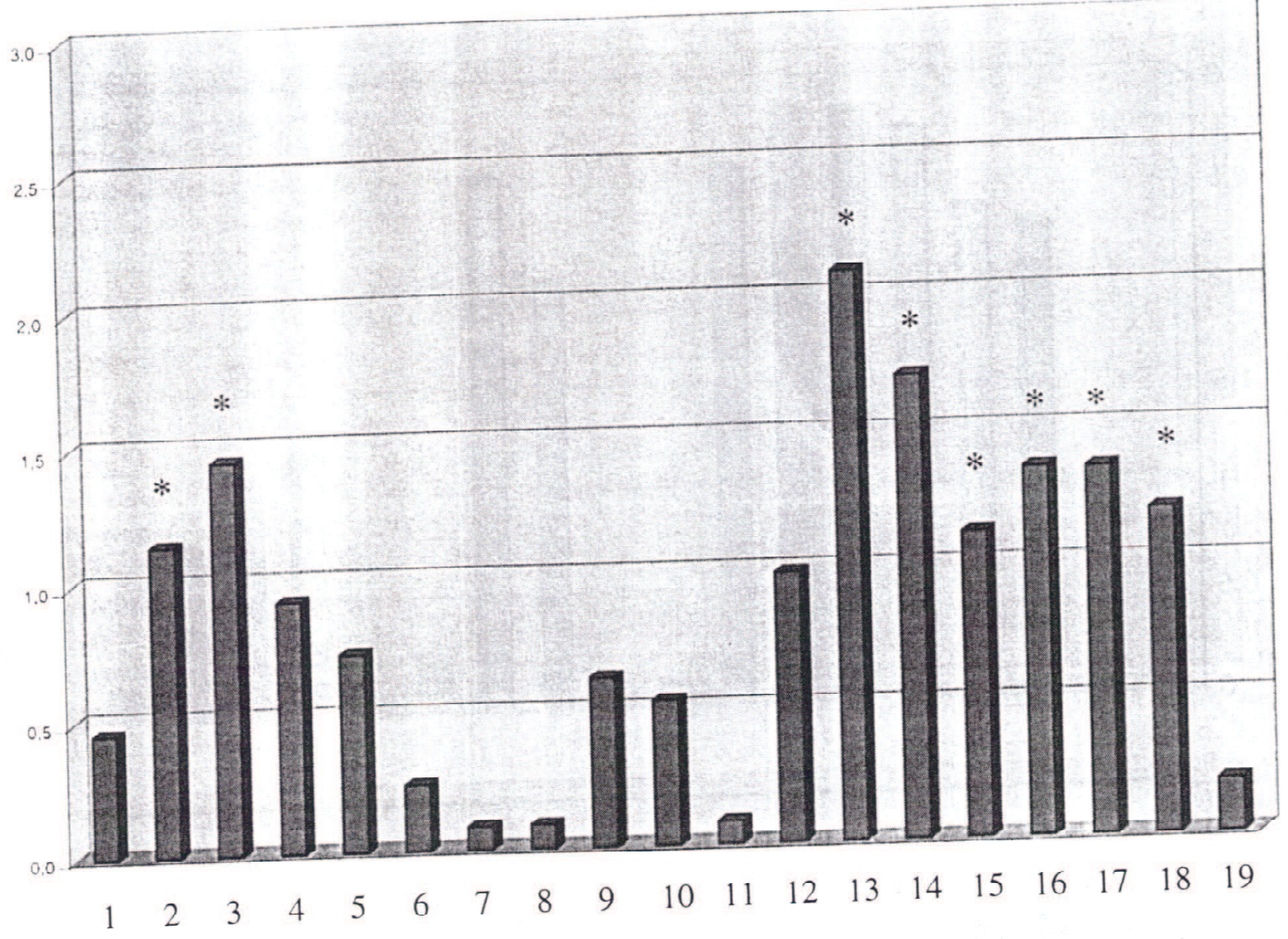

1. ACLSV specific ELOSA detection of RT-PCR amplification products obtained from crude extracts of leaves of apple tree B8 with primer pair ACLSV5F-8R. Branch 1 (13), Branch 2 (4-6), Branch 3 (7-10), Branch 4 (11-14); leaves with symptoms $(2,5,6,9,10,13,14)$, leaves without symptoms $(1,4,7,8,11,12)$. Positive controls: leaves of Chenopodium quinoa infected with ACLSV P863 $(15,16)$ or of apple tree 91328 $(17,18)$. Blank (19). Crude sap diluted 10x (odd numbers) or $100 \mathrm{x}$ (even numbers). All the RT-PCR amplification products have been diluted $10 \mathrm{x}$ before revelation by ELOSA. ${ }^{*}=$ samples revealed positive by ELISA tests made on aliquots of the same material). 

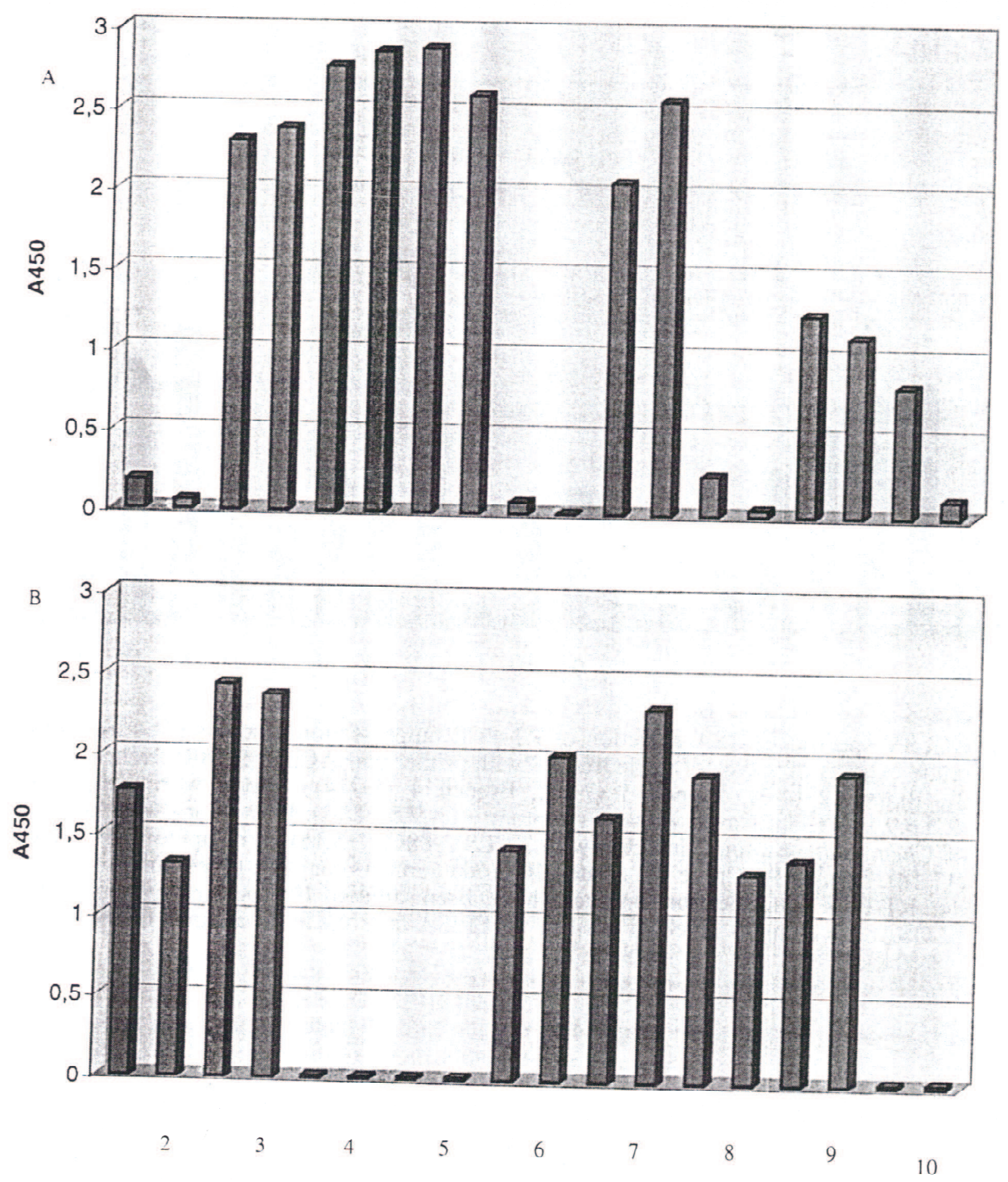

2. ELOSA detection of RT-PCR amplification products obtained from crude extracts of leaves of Prunus trees with primer pairs PNRSV10F-10R (A) or PDV17F-12R (B). Plum trees H2 $(2,3), \mathrm{H} 4(4,5)$ and $\mathrm{I} 5(6,7)$ or cherry tree I6 $(8,9)$. Crude extracts diluted $10 x$ (even numbers) or 100x (odd numbers). Blank (10). Revclation by ELOSA was performed without dilution of RT-PCR amplification products. 